\title{
Trichostatin A induces apoptotic cell death of HeLa cells in a Bcl-2 and oxidative stress-dependent manner
}

\author{
BO RA YOU and WOO HYUN PARK
}

\author{
Department of Physiology, Medical School, Research Institute for Endocrine Sciences, \\ Chonbuk National University, JeonJu 561-180, Republic of Korea
}

Received August 29, 2012; Accepted October 26, 2012

DOI: $10.3892 /$ ijo.2012.1705

\begin{abstract}
Trichostatin A (TSA) as a HDAC inhibitor can regulate many biological properties including apoptosis and cell proliferation in various cancer cells. Here, we evaluated the effect of TSA on the growth and death of HeLa cervical cancer cells in relation to reactive oxygen species (ROS) and glutathione (GSH) levels. Dose- and time-dependent growth inhibition was observed in HeLa cells with an $\mathrm{IC}_{50}$ of approximately $20 \mathrm{nM}$ at $72 \mathrm{~h}$. This agent also induced apoptotic cell death, as evidenced by annexin V-FITC staining cells, caspase-3 activation and the loss of mitochondrial membrane potential (MMP; $\Delta \Psi_{\mathrm{m}}$ ). In addition, the administration of Bcl-2 siRNA intensified TSA-induced HeLa cell death. All of the tested caspase inhibitors significantly rescued some cells from TSA-induced HeLa cell death. TSA increased $\mathrm{O}_{2}{ }^{--}$level and induced GSH depletion in HeLa cells. Caspase inhibitors significantly attenuated $\mathrm{O}_{2}{ }^{-}$ level and GSH depletion in TSA-treated HeLa cells. In addition, $\mathrm{N}$-acetyl cysteine (NAC; a well known antioxidant) significantly prevented cell death and GSH depletion in TSA-treated HeLa cells via decreasing $\mathrm{O}_{2}^{--}$level. In conclusion, TSA inhibited the
\end{abstract}

Correspondence to: Professor Woo Hyun Park, Department of Physiology, Medical School, Research Institute for Endocrine Sciences, Chonbuk National University, JeonJu 561-180, Republic of Korea

E-mail: parkwh71@chonbuk.ac.kr

Abbreviations: TSA, trichostatin A; HAT, histone acetyltransferase; HDAC, histone deacetylase; ROS, reactive oxygen species; MMP $\left(\Delta \Psi_{\mathrm{m}}\right)$, mitochondrial membrane potential; FBS, fetal bovine serum; MTT,3-(4,5-dimethylthiazol-2-yl)-2,5-diphenyltetrazolium bromide; PI, propidium iodide; FITC, fluorescein isothiocyanate; Z-VAD-FMK, benzyloxycarbonyl-Val-Ala-Asp-fluoromethylketone;Z-DEVD-FMK, benzyloxycarbonyl-Asp-Glu-Val-Asp-fluoromethylketone; Z-IETD-FMK,benzyloxycarbonyl-Ile-Glu-Thr-Asp-fluoromethylketone; Z-LEHD-FMK, benzyloxycarbonyl-Leu-Glu-His-Asp-fluoromethylketone; DHE, dihydroethidium; GSH, glutathione; CMFDA, 5-chloromethylfluorescein diacetate; Trx, thioredoxin; TrxR, thioredoxin reductase; $\mathrm{Cu} / \mathrm{Zn}$ SOD, copper zinc superoxide dismutase; $\mathrm{Mn}$ $\mathrm{SOD}$, manganese superoxide dismutase; NAC, N-acetyl cysteine

Key words: trichostatin A, histone deacetylase, apoptosis, HeLa, reactive oxygen species growth of HeLa cells via Bcl-2-mediated apoptosis, which was closely related to $\mathrm{O}_{2}{ }^{--}$and $\mathrm{GSH}$ content levels.

\section{Introduction}

Histone acetylation is an important step in the initiation of transcription (1). The acetylation of lysine residues in histones weakens their binding to DNA and leads to euchromatin structure, which induces transcriptional factors to bind to promoter regions of genes (2). Two opposing enzyme activities of histone acetyltransferases (HATs) and histone deacetylases (HDACs) determine the acetylation status of histones, respectively, acetylating or deacetylating the epsilon-amino groups of lysine residues located in the amino-terminal tails of the histones (2). It was reported that dysregulation of HDAC activity can cause the silence of tumor suppressor genes such as p53 and contribute to cancer initiation $(3,4)$. Previous studies have demonstrated that HDAC activity and expression are increased in many human cancers including prostate and pancreatic cancer $(5,6)$. Therefore, HDAC inhibitors have been considered as novel anticancer drugs. In particular, the reversible HDAC inhibitor, trichostatin A (TSA) and its hydroxamate analogues can effectively and selectively induce tumor growth arrest at very low concentrations (nano- to micromolar range) (7). In fact, vorinostat (suberoylanilide hydroxamic acid) has been used for the treatment of cutaneous T-cell lymphoma (8). Other types of HDAC inhibitors such as romidepsin, panobinostat and valproic acid are clinically evaluated in cancer therapy $(9,10)$. In general, HDAC inhibitors can induce cell cycle arrest, cell death and cell differentiation in various cancer cells (11-13). They have also been shown to generate reactive oxygen species (ROS) in solid tumor and leukemia cells (14). Excessive production of ROS, which is called oxidative stress, has been recognized to induce cell death.

Cervical cancer is a major cause of cancer-related death in women worldwide and the occurrence of this cancer is ascribed to the changes of genetic and epigenetic events. Epigenetic alterations such as global DNA hypomethylation, hypermethylation of tumor suppressor genes and histone modifications take place during cervical carcinogenesis (15). It was reported that phosphorylated and acetylated forms of histone $\mathrm{H} 3$ in cytologic smears are related to the progression of cervical cancer (16). Furthermore, the overexpression of HDAC2 is observed in cervical cancer (17). It has been reported that TSA 
has anticancer effect in liver, colorectal and breast cancer cells in vitro and in vivo (18-20). However, little is known about the anticancer effect of TSA in cervical cancer cells in view of ROS and GSH levels. Therefore, in the present study, we investigated the effects of TSA on cell growth and death in human cervical HeLa cells in relation to ROS and GSH levels.

\section{Materials and methods}

Cell culture. Human cervical adenocarcinoma HeLa cells were obtained from the American Type Culture Collection (ATCC, Manassas, VA) and maintained in a humidified incubator containing $5 \% \mathrm{CO}_{2}$ at $37^{\circ} \mathrm{C}$. HeLa cells were cultured in RPMI1640 (Sigma-Aldrich Chemical Co.,St.Louis, MO) supplemented with $10 \%$ fetal bovine serum (FBS; Sigma-Aldrich) and $1 \%$ penicillin-streptomycin (Gibco BRL, Grand Island, NY). Cells were routinely grown in 100-mm plastic tissue culture dishes (Nunc, Roskilde, Denmark) and harvested with a solution of trypsin-EDTA while in a logarithmic phase of growth.

Reagents. TSA was purchased from Cayman Chemical Co. (Ann Arbor, MI) and was dissolved in dimethl sulfoxide (DMSO; Sigma-Aldrich) at $100 \mathrm{mM}$ as a stock solution. The pan-caspase inhibitor (Z-VAD-FMK; benzyloxycarbonylVal-Ala-Asp-fluoromethylketone), caspase-3 inhibitor (Z-DEVD-FMK; benzyloxycarbonyl-Asp-Glu-Val-Aspfluoromethylketone), caspase-8 inhibitor (Z-IETD-FMK; benzyloxycarbonyl-Ile-Glu-Thr-Asp-fluoromethylketone) and caspase-9 inhibitor (Z-LEHD-FMK; benzyloxycarbonyl-LeuGlu-His-Asp-fluoromethylketone) were obtained from R\&D Systems, Inc. (Minneapolis, MN) and were dissolved in DMSO at $10 \mathrm{mM}$ to act as stock solutions. NAC was also obtained from Sigma-Aldrich. NAC was dissolved in the buffer $20 \mathrm{mM}$ HEPES ( $\mathrm{pH}$ 7.0)] at $100 \mathrm{mM}$ as a stock solution. Cells were pretreated with each caspase inhibitor or NAC for $1 \mathrm{~h}$ prior to TSA treatment. DMSO $(0.05 \%)$ was used as a control vehicle.

Growth inhibition assay. Cell growth changes were determined by measuring 3-(4,5-dimethylthiazol-2-yl)-2,5-diphenyltetrazolium bromide dye (MTT; Sigma-Aldrich) absorbance in living cells. In brief, $5 \times 10^{3}$ cells were seeded in 96-well microtiter plates (Nunc) for MTT assays. After exposure to the designated doses of TSA with or without $15 \mu \mathrm{M}$ of a given caspase inhibitor or $2 \mathrm{mM}$ NAC for the indicated times, $20 \mu \mathrm{l}$ of MTT solution [2 $\mathrm{mg} / \mathrm{ml}$ in phosphate-buffered saline (PBS)] were added to each well of 96-well plates. The plates were incubated for 4 additional hours at $37^{\circ} \mathrm{C}$. Medium in plates was withdrawn using pipetting and $200 \mu \mathrm{l}$ DMSO was added to each well to solubilize the formazan crystals. Optical density was measured at $570 \mathrm{~nm}$ using a microplate reader $\left(\right.$ Synergy ${ }^{\mathrm{TM}} 2$, BioTek Instruments Inc., Winooski, VT).

Measurement of HDAC activity. HDAC activity was assessed using the HDAC Assay kit (Millipore, Billerica, MA), according to the manufacturer's instructions. In brief, $1 \times 10^{6}$ cells in $60-\mathrm{mm}$ culture dish (Nunc) were incubated with the indicated doses of TSA for $72 \mathrm{~h}$. The cells were then washed in PBS and suspended in 5 volumes of lysis buffer (R\&D Systems, Inc.). Protein concentrations were determined using the Bradford method. Supernatant samples containing $20 \mu \mathrm{g}$ of total protein were used for determination of HDAC activity. These samples were added to each well in 96-well microtiter plates (Nunc) with HDAC substrate provided by the assay kit at $37^{\circ} \mathrm{C}$ for $1 \mathrm{~h}$. The optical density of each well was measured at $405 \mathrm{~nm}$ using a microplate reader (Synergy 2, BioTek Instruments).

Western blot analysis. The expression levels of proteins were evaluated using western blot analysis. In brief, $1 \times 10^{6}$ cells in 60-mm culture dish (Nunc) were incubated with the designated doses of TSA for $72 \mathrm{~h}$. The cells were then washed in PBS and suspended in 5 vol of lysis buffer (20 mM HEPES. pH 7.9, $20 \%$ glycerol, $200 \mathrm{mM} \mathrm{KCl}, 0.5 \mathrm{mM}$ EDTA, 0.5\% NP40, $0.5 \mathrm{mM}$ DTT, $1 \%$ protease inhibitor cocktail). Supernatant protein concentrations were determined using the Bradford method. Supernatant samples containing $30 \mu \mathrm{g}$ total protein were resolved by 10 or $15 \%$ SDS-PAGE gels depending on the sizes of target proteins, transferred to Immobilon-P PVDF membranes (Millipore) by electroblotting and then probed with anti-acetylated H3, anti-acetylated H4 (Millipore), anti-Bax (Cell Signaling, Beverly, MA), anti-Bcl-2, anti-PARP, anti-Trx1, anti-Trx2, anti-TrxR1, anti-Cu/Zn SOD, anti-Mn SOD and anti- $\beta$-actin antibodies (Santa Cruz Biotechnology, Santa Cruz, CA). Membranes were incubated with horseradish peroxidaseconjugated secondary antibodies. Blots were developed using an ECL kit (Amersham, Arlington Heights, IL). Quantitative data were obtained using an imaging densitometer (ImageJ version 1.33 software, $\mathrm{NIH}$ ).

Sub-G1 cell analysis. Sub-G1 cells were determined by propidium iodide (PI, Sigma-Aldrich; Ex/Em=488/617 nm) staining. In brief, $1 \times 10^{6}$ cells in $60-\mathrm{mm}$ culture dish (Nunc) were incubated with the designated doses of TSA for $72 \mathrm{~h}$. Cells were then washed with PBS and fixed in $70 \%$ ethanol. Cells were washed again with PBS and then incubated with PI $(10 \mu \mathrm{g} / \mathrm{ml})$ with RNase at $37^{\circ} \mathrm{C}$ for $30 \mathrm{~min}$. The sub-G1 DNA content cells were measured with a FACStar flow cytometer (Becton-Dickinson, San Jose, CA).

Annexin $V$ staining. Apoptotic cell death was determined by staining cells with annexin V-fluorescein isothiocyanate (FITC, Invitrogen Molecular Probes, OR; Ex/Em = 488/519 nm). In brief, $1 \times 10^{6}$ cells in $60-\mathrm{mm}$ culture dish (Nunc) were incubated with the designated doses of TSA with or without $15 \mu \mathrm{M}$ of a given caspase inhibitor or $2 \mathrm{mM} \mathrm{NAC}$ for $72 \mathrm{~h}$. Cells were washed twice with cold PBS and then resuspended in $500 \mu \mathrm{l}$ of binding buffer (10 mM HEPES/NaOH pH 7.4, $140 \mathrm{mM} \mathrm{NaCl}$, $2.5 \mathrm{mM} \mathrm{CaCl}$ ) at a concentration of $1 \times 10^{6}$ cells $/ \mathrm{ml}$. Annexin V-FITC $(5 \mu \mathrm{l})$ and PI $(1 \mu \mathrm{g} / \mathrm{ml})$ were then added to these cells. Stained cells with annexin V-FITC were analyzed with a FACStar flow cytometer (Becton-Dickinson).

Quantification of caspase-3 activity. The activity of caspase-3 was assessed using the caspase- 3 colorimetric assay kit (R\&D Systems). In brief, $1 \times 10^{6}$ cells in $60 \mathrm{~mm}$ culture dish (Nunc) were incubated with $50 \mathrm{nM}$ TSA for $72 \mathrm{~h}$. The cells were then washed in PBS and suspended in 5 vol of lysis buffer provided by the kit. Protein concentrations were determined using the Bradford method. Supernatant samples containing $50 \mu \mathrm{g}$ of total protein were used for determination of caspase- 3 activity. These were added to each well in 96-well microtiter plates 
A

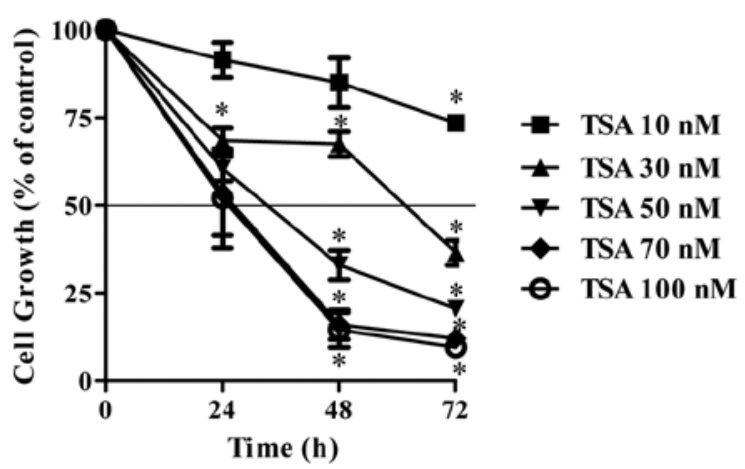

B

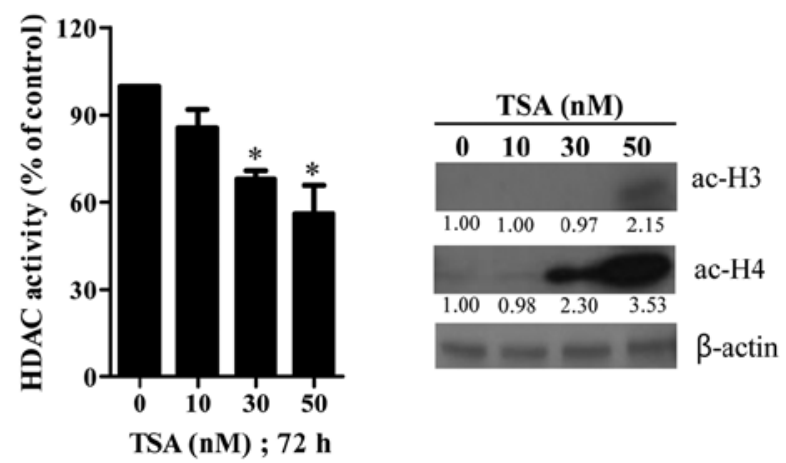

Figure 1. Effects of TSA on cell growth and HDAC activity in HeLa cells. Exponentially growing cells were treated with the designed concentration of TSA for indicated times. (A) The graph shows cellular growth changes in HeLa cells, as assessed by MTT assay. (B) The graph shows HDAC activity in HeLa cells. The inside figure indicates the levels of acetylated $\mathrm{H} 3$ and $\mathrm{H} 4$ proteins in TSA-treated HeLa cells. Samples of protein extracts (30 $\mu \mathrm{g})$ were resolved by SDS-PAGE gel, transferred onto PVDF membranes and immunoblotted with the indicated antibodies against ac-H3, ac-H4 and $\beta$-actin. The expression levels of ac-H3 and $\mathrm{H} 4$ proteins were quantified using a densitometer, Image J software. The relative levels were calculated as the ratio of ac-H3 and ac-H4 to $\beta$-actin protein level, respectively. ${ }^{*}$ p $<0.05$ compared with the control group.

(Nunc) with DEVD-pNA as a caspase-3 substrate at $37^{\circ} \mathrm{C}$ for $1 \mathrm{~h}$. The optical density of each well was measured at $405 \mathrm{~nm}$ using a microplate reader (Synergy 2, BioTek Instruments). Caspase-3 activity was expressed in arbitrary absorbance units.

Measurement of $M M P\left(\Delta \Psi_{m}\right) \cdot \operatorname{MMP}\left(\Delta \Psi_{\mathrm{m}}\right)$ levels were measured using a rhodamine 123 fluorescent dye (Sigma-Aldrich; Ex/ $\mathrm{Em}=485 / 535 \mathrm{~nm}$ ). In brief, $1 \times 10^{6}$ cells in $60-\mathrm{mm}$ culture dish (Nunc) were incubated with the designated doses of TSA with or without $15 \mu \mathrm{M}$ of a given caspase inhibitor or $2 \mathrm{mM}$ NAC for $72 \mathrm{~h}$. Cells were washed twice with PBS and incubated with a rhodamine $123(0.1 \mu \mathrm{g} / \mathrm{ml})$ at $37^{\circ} \mathrm{C}$ for $30 \mathrm{~min}$. The cells were washed again twice with PBS and then resuspended in $500 \mu \mathrm{l}$ of PBS buffer. Rhodamine 123 staining intensity was determined by the flow cytometry (Becton-Dickinson). An absence (-) of rhodamine 123 fluorescence in cells was expressed as the loss of MMP $\left(\Delta \Psi_{\mathrm{m}}\right)$ in the cells.

Transfection of cells with Bax and Bcl-2 siRNAs. Gene silencing of Bax and Bcl-2 was performed using a siRNA knockdown system. A non-specific control siRNA duplex [5'-CCUACGCC ACCAAUUUCGU(dTdT)-3'], Trx1 siRNA duplex [5'-GCAU GCCAACAUUCCAGUU(dTdT)-3'], Bax siRNA duplex [5'-GCUGGACAUUGGACUUCCU(dTdT)-3'] and Bcl-2 siRNA duplex [5'-CAGAAGUCUGGGAAUCGAU(dTdT)-3'] were purchased from the Bioneer Corp. (Daejeon, South Korea). In brief, $2.5 \times 10^{5}$ cells in 6-well plates (Nunc) were incubated in RPMI-1640 supplemented with 10\% FBS. The next day, cells ( $\sim 30-40 \%$ confluence) in each well were transfected with the control, Bax or Bcl-2 siRNA [80 pmol in Opti-MEM (Gibco BRL)] using Lipofectamine 2000, according to the manufacturer's instructions (Invitrogen, Brandford, CT). One day later, cells were treated with or without $100 \mathrm{nM}$ TSA for additional $24 \mathrm{~h}$. The transfected cells were collected and used for western blot analysis, growth inhibition assay, annexin-FITC staining, $\mathrm{O}_{2}{ }^{--}$and GSH level measurements.
Detection of intracellular $\mathrm{O}_{2}^{--}$levels. Intracellular $\mathrm{O}_{2}{ }^{--}$levels were detected by means of an oxidation-sensitive fluorescent probe dye, dihydroethidium (DHE, Invitrogen Molecular Probes; Ex/ $\mathrm{Em}=518 / 605 \mathrm{~nm}$ ). In brief, $1 \times 10^{6}$ cells in $60-\mathrm{mm}$ culture dish (Nunc) were incubated with the designated doses of TSA with or without $15 \mu \mathrm{M}$ of a given caspase inhibitor or $2 \mathrm{mM}$ NAC for $72 \mathrm{~h}$. Cells were then washed in PBS and incubated with $20 \mu \mathrm{M}$ $\mathrm{DHE}$ at $37^{\circ} \mathrm{C}$ for $30 \mathrm{~min}$. The intensity of DHE fluorescence was detected using a FACStar flow cytometer (Becton-Dickinson). $\mathrm{O}_{2}^{--}$levels were expressed as mean fluorescence intensity (MFI), which was calculated by CellQuest software (Becton-Dickinson).

Detection of intracellular glutathione (GSH) levels. Cellular GSH levels were analyzed using a 5-chloromethylfluorescein diacetate dye (CMFDA, Invitrogen Molecular Probes; Ex/Em = $522 / 595 \mathrm{~nm}$ ). In brief, $1 \times 10^{6}$ cells in $60 \mathrm{~mm}$ culture dish (Nunc) were incubated with the designated doses of TSA with or without $15 \mu \mathrm{M}$ of a given caspase inhibitor or $2 \mathrm{mM}$ NAC for $72 \mathrm{~h}$. Cells were then washed with PBS and incubated with $5 \mu \mathrm{M}$ CMFDA at $37^{\circ} \mathrm{C}$ for $30 \mathrm{~min}$. CMF fluorescence intensity was determined using a FACStar flow cytometer (Becton-Dickinson). Negative CMF staining cells indicating GSH depletion were expressed as the percents of (-) CMF cells.

Statistical analysis. The results represent the mean of at least three independent experiments (mean \pm SD). The data were analyzed using Instat software (GraphPad Prism4, San Diego, CA). The Student's t-test or one-way analysis of variance (ANOVA) with post hoc analysis using the Tukey multiple comparison test was used for parametric data. Statistical significance was defined as $\mathrm{p}<0.05$.

\section{Results}

Effects of TSA on the growth and HDAC activity in HeLa cells. We first examined the effect of TSA on the growth inhibition of HeLa cells using MTT assays. After exposure to the various concentrations of TSA, HeLa cell growth was dose- and time- 
A

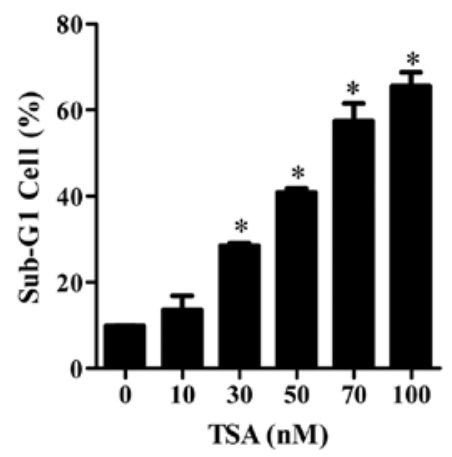

C

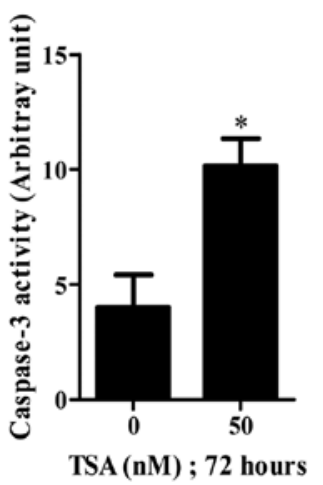

B

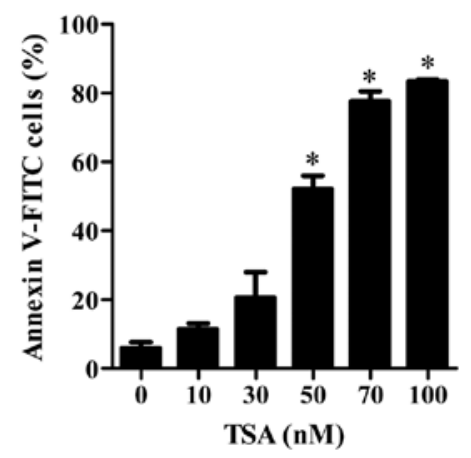

D

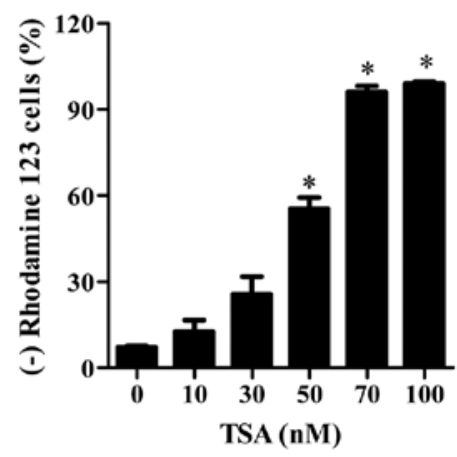

Figure 2. Effects of TSA on cell death and MMP $\left(\Delta \Psi_{\mathrm{m}}\right)$ in HeLa cells. Exponentially growing cells were treated with the designed concentrations of TSA for $72 \mathrm{~h}$. (A and B) The graphs show the percents of sub-G1 and annexin V-positive cells, respectively. (C) The graph shows the activity of caspase-3 in samples containing $50 \mu \mathrm{g}$ of total protein. Western blot analysis shows the levels of Bcl-2, Bax, PARP and $\beta$-actin. (D) The graph shows the percents of rhodamine 123-negative $\left[\mathrm{MMP}\left(\Delta \Psi_{\mathrm{m}}\right)\right.$ loss] cells. ${ }^{*} \mathrm{p}<0.05$ compared with the control group.

dependently decreased with an $\mathrm{IC}_{50}$ of $\sim 100,40$ and $20 \mathrm{nM}$ at 24, 48 and 72 h, respectively (Fig. 1A). When tested whether TSA as an HDAC inhibitor would inhibit HDAC activity, TSA significantly attenuated the HDAC activity at $72 \mathrm{~h}$ (Fig. 1B). Furthermore, it was observed that TSA increased the forms of acetylated histone 3 and 4 in HeLa cells (Fig. 1B).

Effects of TSA on cell death and MMP $\left(\Delta \Psi_{m}\right)$ in HeLa cells. As shown in Fig. 2A, TSA increased the number of sub-G1 cells in HeLa cells in a dose-dependent manner at $72 \mathrm{~h}$. When HeLa cells were stained with annexin V-FITC to evaluate the induction of apoptosis, the number of annexin $\mathrm{V}$-staining cells in TSA-treated cells was dose-dependently increased (Fig. 2B). In addition, caspase-3 activity was increased in $50 \mathrm{nM}$ TSA-treated HeLa cells (Fig. 2C). Examination of apoptosis-related protein changes during TSA-induced cell death revealed that the levels of Bcl-2 and the intact $116 \mathrm{kDa}$ form of poly(ADP-ribose) polymerase (PARP) were decreased by TSA whereas the level of Bax protein was not strongly altered (Fig. 2C). Moreover, TSA increased the number of MMP $\left(\Delta \Psi_{\mathrm{m}}\right)$ loss cells in HeLa cells at $72 \mathrm{~h}$ in a dosedependent manner (Fig. 2D).

Effects of Bax and Bcl-2 siRNAs on cell growth and death in TSA-treated HeLa cells. To investigate the effects of Bax and Bcl-2 on HeLa cell growth and death, HeLa cells were transfected with either non-target control siRNA, Bax or Bcl-2
siRNA. As shown in Fig. 3A, the expressions of Bax and Bcl-2 were clearly decreased by each siRNA as compared with cells transfected with control siRNA. When we observed the effect of Bax or Bcl-2 siRNA on cell growth and death in TSA-treated HeLa cells, Bax siRNA significantly attenuated cell growth inhibition and death by TSA (Fig. 3B and C). On the other hand, Bcl-2 siRNA markedly intensified cell growth inhibition and death in TSA-treated HeLa cells (Fig. 3B and C). In addition, the administration of Bcl-2 siRNA alone induced cell growth inhibition and death in the control HeLa cells (Fig. 3B and C).

Effects of TSA on intracellular $\mathrm{O}_{2}{ }^{--}$and GSH levels in HeLa cells. The intracellular $\mathrm{O}_{2}^{--}$levels were measured in TSA-treated HeLa cells using a DHE fluorescence dye. As shown in Fig. 4A, the $\mathrm{O}_{2}^{--}$level was significantly increased in TSA-treated HeLa cells at $72 \mathrm{~h}$ in a dose-dependent manner. In addition, the level of Mn SOD was upregulated by TSA (Fig. 4B). However, this agent did not strongly influence the levels of other tested antioxidant proteins; Trx1, Trx2, TrxR1 and Cu/Zn SOD (Fig. 4B). In relation to GSH level in TSA-treated HeLa cells, TSA significantly increased GSH depleted cell number at $72 \mathrm{~h}$ in a dose-dependent manner (Fig. 4C).

Effects of caspase inhibitors on cell growth, death, $\mathrm{O}_{2}{ }^{--}$and GSH levels in TSA-treated HeLa cells. We determined which caspases were involved in the cell growth inhibition and death 
A
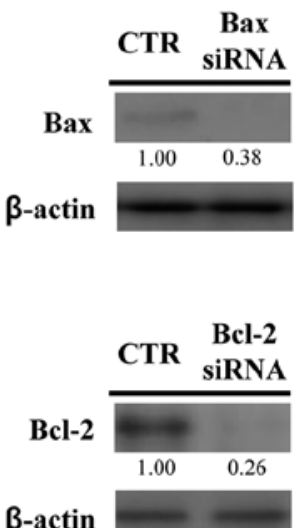

B

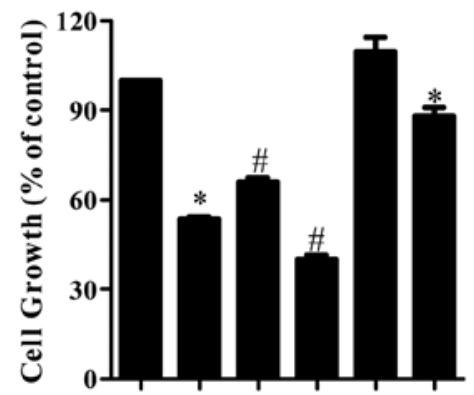

TSA $100 \mathrm{nM}:-+++-\quad+$

Bax siRNA : - $-+\quad+\quad+\quad+$
C

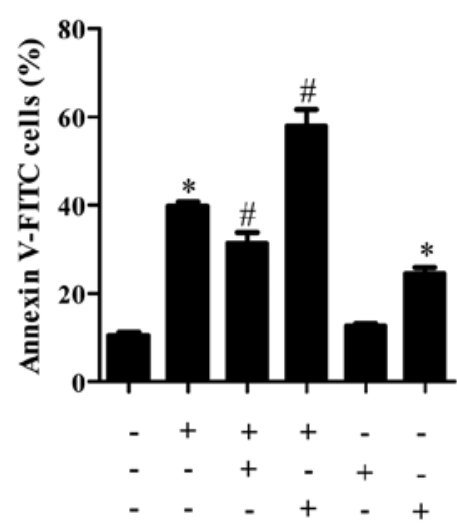

Figure 3. Effect of Bax and Bcl-2 siRNAs on cell growth and death in TSA-treated HeLa cells. HeLa cells ( $30-40 \%$ confluence) were transfected with nontarget control (CTR), Bax or Bcl-2 siRNA. One day later, cells were treated with $100 \mathrm{nM}$ TSA for an additional $24 \mathrm{~h}$. (A) The expressions of Bax and Bcl-2 were examined by western blot analysis. Protein extracts $(30 \mu \mathrm{g})$ were resolved by SDS-PAGE gel, transferred onto PVDF membranes and immunoblotted with the indicated antibodies against Bax, Bcl-2 and $\beta$-actin. (B and C) The graphs show the cell growth (B) and percent of annexin V-positive staining cells (C) in HeLa cells. ${ }^{\mathrm{p}}<0.05$ compared with the control group. ${ }^{\#} \mathrm{p}<0.05$ compared with cells treated with TSA only.

A

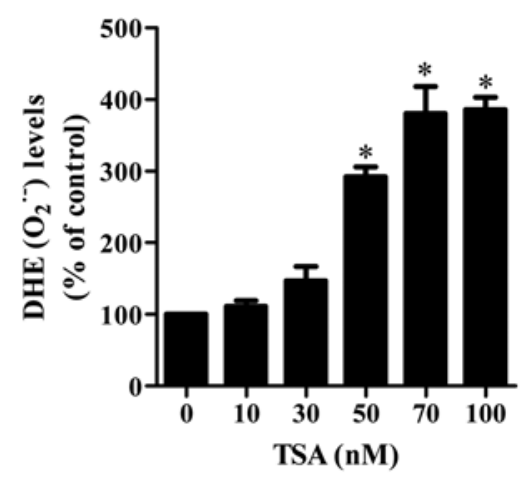

B

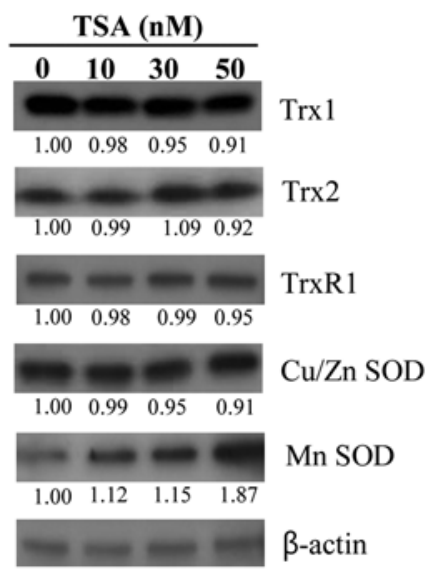

C

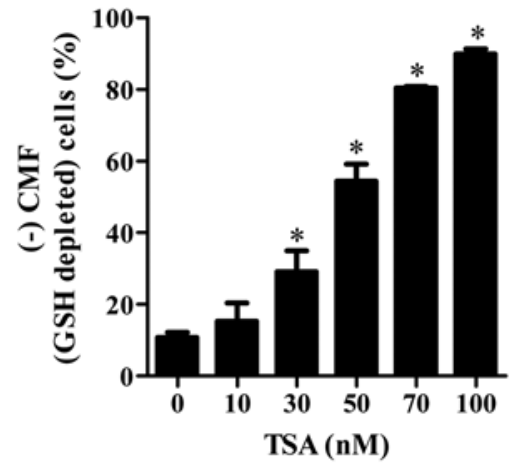

Figure 4. Effects of intracellular $\mathrm{O}_{2}{ }^{-*}$ and GSH levels in HeLa cells. Exponentially growing cells were treated with the designed concentrations of TSA for $72 \mathrm{~h}$. The intracellular $\mathrm{O}_{2}{ }^{-*}$ and GSH levels were measured using a FACStar flow cytometer. (A) The graph indicates $\mathrm{O}_{2}{ }^{-*}$ (DHE) level compared with control cells. (B) Western blot analysis shows the levels of Trx1, Trx2, TrxR1, Cu/Zn SOD, Mn SOD and $\beta$-actin. (C) The graph shows the percents of (-) CMF (GSH depleted) cells. ${ }^{*} \mathrm{p}<0.05$ compared with the control group.

of TSA-treated HeLa cells. For this experiment, we chose $50 \mathrm{nM}$ TSA as a suitable dose to differentiate the level of cell growth and death in the presence or absence of each caspase inhibitor; [pan-caspase inhibitor (Z-VAD), caspase-3 inhibitor (Z-DEVD), caspase-8 inhibitor (Z-IETD), or caspase-9 inhibitor (Z-LEHD)]. A concentration of $15 \mu \mathrm{M}$ caspase inhibitor was used as an optimal dose in this study, this dose did not significantly affect cell death in HeLa control cells. All the caspase inhibitors attenuated cell growth inhibition and death in TSA-treated HeLa cells (Fig. 5A and B). In relation to $\mathrm{O}_{2}{ }^{--}$and GSH levels, all caspase inhibitors, especially Z-VAD, Z-DEVD and Z-IETD significantly reduced $\mathrm{O}_{2}{ }^{-}$level in TSA-treated HeLa cells (Fig. 5C). Furthermore, all the caspase inhibitors markedly prevented GSH depletion in TSA-treated HeLa cells (Fig. 5D).

Effects of NAC on cell growth, death, $\mathrm{O}_{2}{ }^{-}$and GSH levels in TSA-treated HeLa cells. To investigate the involvement of
$\mathrm{O}_{2}{ }^{-}$level increase in TSA-induced HeLa cell growth inhibition and death, HeLa cells were pretreated with $2 \mathrm{mM}$ NAC as an antioxidant before the treatment of TSA. As shown in Fig. 6A and B, NAC significantly recovered cell growth inhibition and death in TSA-treated HeLa cells. In addition, NAC attenuated the proportion of MMP $\left(\Delta \Psi_{\mathrm{m}}\right)$ loss cells in TSA-treated HeLa cells (Fig. 6C). When assessed whether NAC influences $\mathrm{O}_{2}{ }^{-}$and GSH levels, NAC markedly reduced $\mathrm{O}_{2}{ }^{--}$level and GSH depletion in TSA-treated HeLa cells (Fig. 6D and E).

\section{Discussion}

In the present study, we focused on assessing the effects of TSA on cell growth inhibition and death in HeLa cervical cancer cells in relation to ROS and GSH levels. Because TSA decreased the level of HDAC activity and increased the levels of acetylated histones in HeLa cells, TSA seemed to 
A
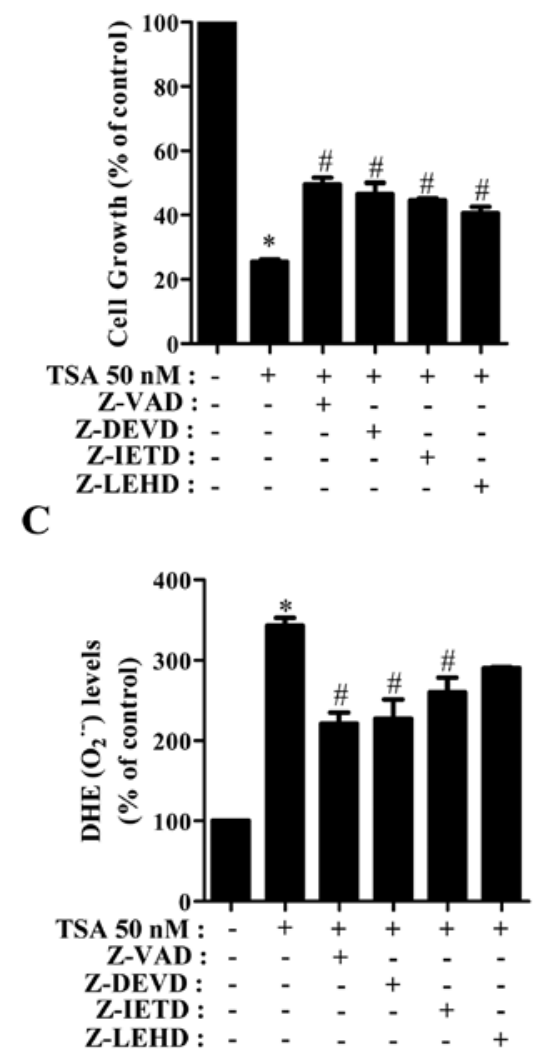

B

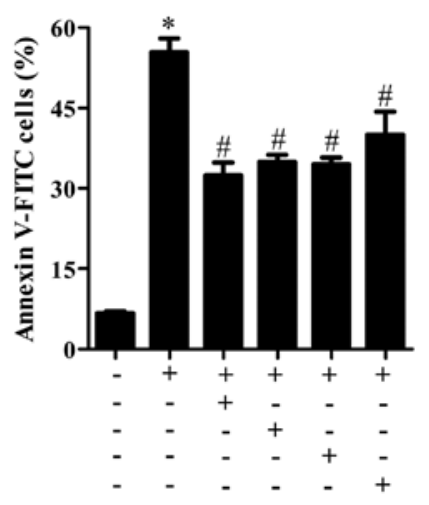

D

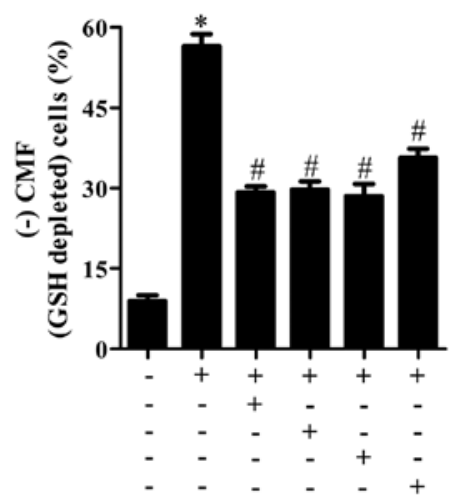

Figure 5. Effects of caspase inhibitors on cell growth, death, $\mathrm{O}_{2}{ }^{-}$and GSH levels in TSA-treated HeLa cells. Exponentially growing cells were treated with $50 \mathrm{nM}$ TSA and/or $15 \mu \mathrm{M}$ of a given caspase inhibitor for $72 \mathrm{~h}$. (A and B) The graphs show the cell growth (A) and percent of annexin V-positive cells in HeLa cells (B). $(\mathrm{C}$ and $\mathrm{D})$ The graphs indicate $\mathrm{O}_{2}{ }^{-}$(DHE) levels (C) and the percents of (-) CMF (GSH-depleted) cells (D). ${ }^{*} \mathrm{p}<0.05$ compared with the control group. ${ }^{*} \mathrm{p}<0.05$ compared with cells treated with TSA only.

A

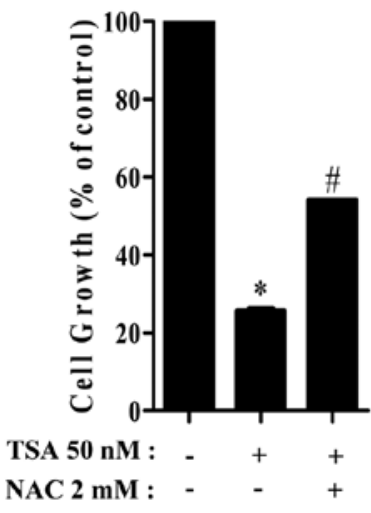

B

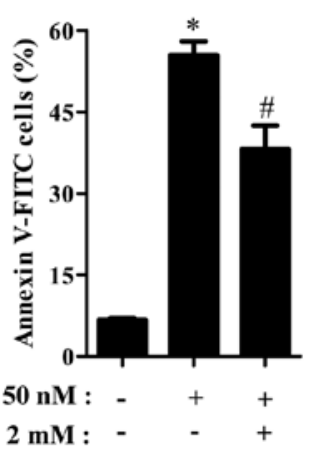

D

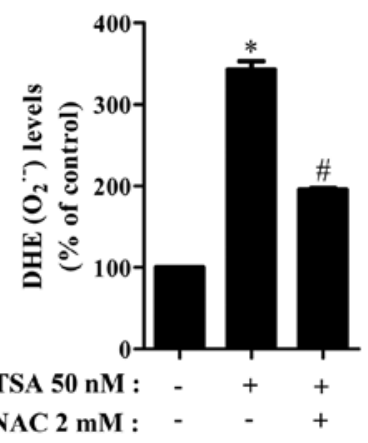

C

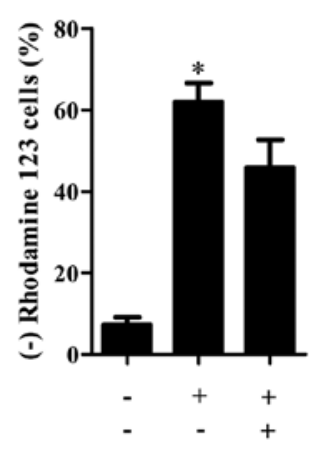

$\mathbf{E}$

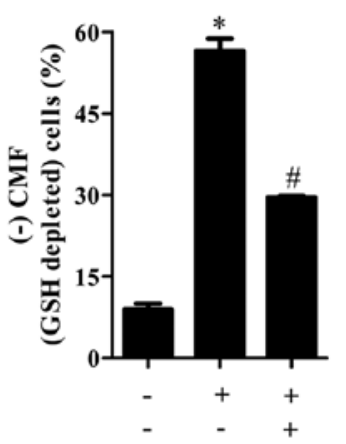

Figure 6. Effects of NAC on cell growth, death, MMP $\left(\Delta \Psi_{\mathrm{m}}\right), \mathrm{O}_{2}{ }^{-}$and GSH levels in TSA-treated HeLa cells. Exponentially growing cells were treated with $50 \mathrm{nM}$ TSA and/or $2 \mathrm{mM}$ NAC for $72 \mathrm{~h}$. (A and B) The graphs show the cell growth (A) and percents of annexin V-positive cells in HeLa cells (B). (C) The graph shows the percents of rhodamine 123-negative [MMP $\left(\Delta \Psi_{\mathrm{m}}\right)$ loss] cells. (D and E) The graphs indicate DHE (O $\left.{ }_{2}^{\circ}\right)$ levels $(\mathrm{D})$ and the percents of $(-) \mathrm{CMF}$ (GSH-depleted) cells (E). ${ }^{*} \mathrm{p}<0.05$ compared with the control group. ${ }^{*} \mathrm{p}<0.05$ compared with cells treated with TSA only. 


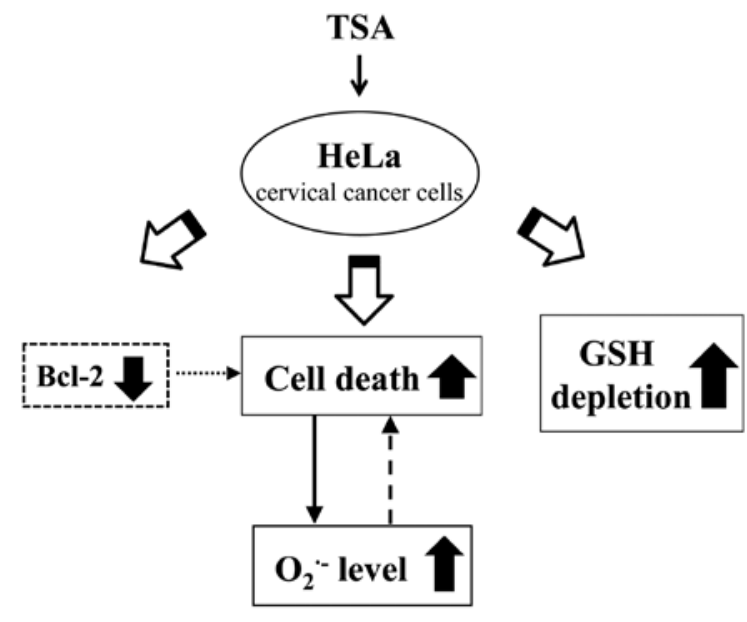

Figure 7. The diagram for TSA-induced HeLa cell death.

act as an HDAC inhibitor in HeLa cells. This agent remarkably induced the acetylation of histone 4 compared with that of histone 3. However, another hydroxamic acid-derived HDAC inhibitor, SBHA strongly induced the acetylation of histone 3 rather than that of histone 4 in HeLa cells (unpublished data). The different effects of TSA and SBHA on the histone acetylation is probably due to the different functional bioavailability of these hydroxamic acid-derived HDAC inhibitors through various biochemical modifications such as sulfation, hydroxylation, oxidation and methylation in cells. TSA inhibited the growth of HeLa cells in a dose- and time-dependent manner and also induced apoptosis. However, this agent did not significantly induce any specific phase arrest of the cell cycle at 24 and $72 \mathrm{~h}$ (data not shown). The growth inhibition in TSA-treated HeLa cells was due to apoptotic cell death rather than a specific cell cycle arrest. TSA dose-dependently triggered the loss of MMP $\left(\Delta \Psi_{\mathrm{m}}\right)$ and reduced MMP $\left(\Delta \Psi_{\mathrm{m}}\right)$ levels in HeLa cells (data not shown). The levels of MMP $\left(\Delta \Psi_{\mathrm{m}}\right)$ loss cells were similar to those of annexin V staining cells (Fig. 2), implying that apoptotic cell death by TSA was tightly correlated with the collapse of $\operatorname{MMP}\left(\Delta \Psi_{\mathrm{m}}\right)$.

A high ratio of $\mathrm{Bax}$ to $\mathrm{Bcl}-2$ is known to be the main trigger in the collapse of MMP $\left(\Delta \Psi_{\mathrm{m}}\right)$ and apoptosis in cells (21). It is reported that HDAC inhibitors downregulate $\mathrm{Bcl}-2$ expression and induce apoptosis in many cancer cells $(22,23)$. Likewise, the level of Bcl-2 protein was downregulated in TSA-treated HeLa cells. Moreover, the administration of Bcl-2 siRNA enhanced the growth inhibition and death of TSA-treated HeLa cells. Therefore, TSA seemed to induce apoptosis in HeLa cells depending on the downregulation of Bcl-2 protein. In relation to Bax protein, TSA did not strongly alter the expression level of Bax protein. However, the administration of Bax siRNA attenuated the growth inhibition and death of TSA-treated HeLa cells. Therefore, these results support the notion that the relatively high ratio of Bax to Bcl-2 can trigger apoptosis in cells. In particular, Bcl-2 siRNA alone induced the growth inhibition and death in HeLa control cells, implying that Bcl-2 protein is a crucial regulator in the survival of HeLa cells. When determined which caspases were involved in apoptosis in TSA-treated HeLa cells, all the tested caspase inhibitors prevented
TSA-induced HeLa cell death. In addition, TSA increased the activity of caspase-3 in HeLa cells. Therefore, TSA-induced HeLa apoptosis is mediated by the activation of various caspase cascades. In particular, both cell death receptor pathway of caspase- 8 and the mitochondrial pathway of caspase- 9 were involved in the induction of apoptosis in HeLa cells.

It is reported that HDAC inhibitor increases ROS levels in solid tumor and leukemia cells (24). Furthermore, oxidative stress seems to be involved in HDAC inhibitor-induced cell death (25). Similarly, the level of $\mathrm{O}_{2}{ }^{--}$was significantly increased in TSA-treated HeLa cells. Probably, the increased $\mathrm{O}_{2}{ }^{-0}$ level mainly resulted from the damage of mitochondria by TSA. Importantly, NAC, which strongly suppressed $\mathrm{O}_{2}{ }^{--}$levels in TSA-treated HeLa cells, significantly prevented HeLa cell growth inhibition and death by TSA and it also attenuated the collapse of MMP $\left(\Delta \Psi_{\mathrm{m}}\right)$. In addition, all caspase inhibitors showing the anti-apoptotic effects decreased $\mathrm{O}_{2}{ }^{--}$levels in these cells. Treatment with Bcl-2 siRNA increased $\mathrm{O}_{2}{ }^{-}$level in TSA-treated HeLa cells whereas treatment with Bax siRNA decreased the $\mathrm{O}_{2}{ }^{--}$level in these cells (data not shown). These results suggested that TSA-induced HeLa cell death is mediated by the oxidative stress derived from $\mathrm{O}_{2}^{--}$level changes.

TSA increased the level of Mn SOD among the various antioxidant proteins in the present study. Mn SOD which is located in mitochondria catalyzes the dismutation of $\mathrm{O}_{2}{ }^{-}$ into oxygen and hydrogen peroxide (26). It is possible that an increase in $\mathrm{O}_{2}{ }^{-}$level in TSA-treated HeLa cells leads to upregulation of the expression of Mn SOD in a compensatory mechanism. However, the expression level of thioredoxin 2 (Trx2), which is another antioxidant enzyme in mitochondria, was not altered by TSA in HeLa cells. Because it has been reported that DNA methylation and histone modification regulated Mn SOD expression in breast cancer cells (27), it is plausible that the specific upregulation of Mn SOD can be transcriptionally regulated by the inhibition of HDAC by TSA.

GSH as the main cellular non-protein antioxidant can eliminate ROS including $\mathrm{O}_{2}{ }^{-}$. It is known that the intracellular GSH content has a decisive effect on anticancer drug-induced apoptosis $(28,29)$. According to our current data, TSA increased the number of GSH depleted cells in HeLa cells. All the tested caspase inhibitors and NAC prevented the GSH depletion by TSA. In addition, treatment with Bcl-2 siRNA increased GSH depletion in TSA-treated HeLa cells whereas treatment with Bax siRNA decreased the GSH depletion in these cells (data not shown). Therefore, these results support the notion that apoptotic effects are inversely comparative to GSH content in the cell.

In conclusion, as depicted in Fig. 7, TSA inhibited the growth of HeLa cervical cancer cells via Bcl-2-mediated and caspase-dependent apoptosis, which was closely related to $\mathrm{O}_{2}{ }^{-}$ and GSH content levels.

\section{Acknowledgements}

This study was supported by the Basic Science Research Program through the National Research Foundation of Korea (NRF) funded by the Ministry of Education, Science and Technology (2010-007059) and by a grant from the Ministry of Science \& Technology (MoST)/Korea Science \& Engineering Foundation (KOSEF) through the Diabetes Research Center at Chonbuk National University (2012-0009323). 


\section{References}

1. Burgess DJ: Histone modification at the gene level. Nat Rev Cancer 12: 156, 2012.

2. Ganesan A, Nolan L, Crabb SJ and Packham G: Epigenetic therapy: histone acetylation, DNA methylation and anti-cancer drug discovery. Curr Cancer Drug Targets 9: 963-981, 2009.

3. Lu Z, Luo RZ, Peng H, Huang M, Nishmoto A, Hunt KK, Helin K, Liao WS and Yu Y: E2F-HDAC complexes negatively regulate the tumor suppressor gene ARHI in breast cancer. Oncogene 25: 230-239, 2006.

4. Khan O and La Thangue NB: HDAC inhibitors in cancer biology: emerging mechanisms and clinical applications. Immunol Cell Biol 90: 85-94, 2012.

5. Lehmann A, Denkert C, Budczies J, Buckendahl AC, DarbEsfahani S, Noske A, Muller BM, Bahra M, Neuhaus P, Dietel M, et al: High class I HDAC activity and expression are associated with RelA/p65 activation in pancreatic cancer in vitro and in vivo. BMC Cancer 9: 395, 2009.

6. Wang L, Zou X, Berger AD, Twiss C, Peng Y, Li Y, Chiu J, Guo H, Satagopan J, Wilton A, et al: Increased expression of histone deacetylaces (HDACs) and inhibition of prostate cancer growth and invasion by HDAC inhibitor SAHA. Am J Transl Res 1: 62-71, 2009.

7. Vanhaecke T, Papeleu P, Elaut G and Rogiers V: Trichostatin A-like hydroxamate histone deacetylase inhibitors as therapeutic agents: toxicological point of view. Curr Med Chem 11: 1629-1643, 2004.

8. Marks PA: Discovery and development of SAHA as an anticancer agent. Oncogene 26: 1351-1356, 2007.

9. Lane AA and Chabner BA: Histone deacetylase inhibitors in cancer therapy. J Clin Oncol 27: 5459-5468, 2009.

10. Campas-Moya C: Romidepsin for the treatment of cutaneous T-cell lymphoma. Drugs Today 45: 787-795, 2009.

11. Pettazzoni P, Pizzimenti S, Toaldo C, Sotomayor P, Tagliavacca L, Liu S, Wang D, Minelli R, Ellis L, Atadja P, et al: Induction of cell cycle arrest and DNA damage by the HDAC inhibitor panobinostat (LBH589) and the lipid peroxidation end product 4-hydroxynonenal in prostate cancer cells. Free Radic Biol Med 50: 313-322, 2011.

12. Phillip CJ, Giardina CK, Bilir B, Cutler DJ, Lai YH, Kucuk O and Moreno CS: Genistein cooperates with the histone deacetylase inhibitor vorinostat to induce cell death in prostate cancer cells. BMC Cancer 12: 145, 2012.

13. Sweet MJ, Shakespear MR, Kamal NA and Fairlie DP: HDAC inhibitors: modulating leukocyte differentiation, survival, proliferation and inflammation. Immunol Cell Biol 90: 14-22, 2012.

14. Gong K, Xie J, Yi H and Li W: CS055 (Chidamide/HBI-8000), a novel histone deacetylase inhibitor, induces G1 arrest, ROS-dependent apoptosis and differentiation in human leukaemia cells. Biochem J 443: 735-746, 2012

15. Duenas-Gonzalez A, Lizano M, Candelaria M, Cetina L, Arce C and Cervera E: Epigenetics of cervical cancer. An overview and therapeutic perspectives. Mol Cancer 4: 38, 2005.
16. Anton M, Horky M, Kuchtickova S, Vojtesek B and Blaha O: Immunohistochemical detection of acetylation and phosphorylation of histone H3 in cervical smears. Ceska Gynekol 69: 3-6, 2004.

17. Huang BH, Laban M, Leung CH, Lee L, Lee CK, Salto-Tellez M, Raju GC and Hooi SC: Inhibition of histone deacetylase 2 increases apoptosis and $\mathrm{p} 21^{\mathrm{Cip} 1 / \mathrm{WAF} 1}$ expression, independent of histone deacetylase 1. Cell Death Differ 12: 395-404, 2005.

18. Vigushin DM, Ali S, Pace PE, Mirsaidi N, Ito K, Adcock I and Coombes RC: Trichostatin A is a histone deacetylase inhibitor with potent antitumor activity against breast cancer in vivo. Clin Cancer Res 7: 971-976, 2001.

19. Zhang CZ, Zhang HT, Chen GG and Lai PB: Trichostatin A sensitizes HBx-expressing liver cancer cells to etoposide treatment. Apoptosis 16: 683-695, 2011.

20. Meng J, Zhang HH, Zhou CX, Li C, Zhang F and Mei QB: The histone deacetylase inhibitor trichostatin A induces cell cycle arrest and apoptosis in colorectal cancer cells via p53-dependent and -independent pathways. Oncol Rep 28: 384-388, 2012

21. Martinou JC and Youle RJ: Mitochondria in apoptosis: Bcl-2 family members and mitochondrial dynamics. Dev Cell 21: 92-101, 2011.

22. Duan H, Heckman CA and Boxer LM: Histone deacetylase inhibitors down-regulate bcl-2 expression and induce apoptosis in $\mathrm{t}(14 ; 18)$ lymphomas. Mol Cell Biol 25: 1608-1619, 2005.

23. Ellis L and Pili R: Histone deacetylase inhibitors: advancing therapeutic strategies in hematological and solid malignancies. Pharmaceuticals 3: 2411-2469, 2010.

24. Eot-Houllier G, Fulcrand G, Magnaghi-Jaulin L and Jaulin C: Histone deacetylase inhibitors and genomic instability. Cancer Lett 274: 169-176, 2009.

25. Ungerstedt JS, Sowa Y, Xu WS, Shao Y, Dokmanovic M, Perez G, Ngo L, Holmgren A, Jiang X and Marks PA: Role of thioredoxin in the response of normal and transformed cells to histone deacetylase inhibitors. Proc Natl Acad Sci USA 102: 673-678, 2005.

26. Miriyala S, Spasojevic I, Tovmasyan A, Salvemini D, Vujaskovic Z, St Clair D and Batinic-Haberle I: Manganese superoxide dismutase, MnSOD and its mimics. Biochim Biophys Acta 1822: 794-814, 2012.

27. Hitchler MJ,Wikainapakul K, Yu L,Powers K, Attatippaholkun W and Domann FE: Epigenetic regulation of manganese superoxide dismutase expression in human breast cancer cells. Epigenetics 1: 163-171, 2006.

28. Brechbuhl HM, Kachadourian R, Min E, Chan D and Day BJ: Chrysin enhances doxorubicin-induced cytotoxicity in human lung epithelial cancer cell lines: the role of glutathione. Toxicol Appl Pharmacol 258: 1-9, 2012.

29. Fath MA, Ahmad IM, Smith CJ, Spence J and Spitz DR: Enhancement of carboplatin-mediated lung cancer cell killing by simultaneous disruption of glutathione and thioredoxin metabolism. Clin Cancer Res 17: 6206-6217, 2011. 